\title{
In vitro assessment of the glucose-lowering effects of berberrubine-9-0- $\beta$-D-glucuronide, an active metabolite of berberrubine
}

Na YANG ${ }^{1}$, Run-bin SUN ${ }^{1}$, Xing-long $\mathrm{CHEN}^{2}$, Le ZHEN ${ }^{1}$, Chun GE ${ }^{1}$, Yu-qing ZHAO ${ }^{1}$, Jun HE ${ }^{1}$, Jian-liang GENG ${ }^{1}$, Jia-hua GUO ${ }^{1}$, Xiao-yi $\mathrm{YU}^{1}$, Fei FEI ${ }^{1}$, Si-qi FENG ${ }^{1}$, Xuan-xuan $\mathrm{ZHU}^{3}$, Hong-bo WANG ${ }^{4}$, Feng-hua FU ${ }^{4}$, Ji-ye $\mathrm{AA}^{1,}{ }^{*}$, Guang-ji WANG

${ }^{1}$ Key Lab of Drug Metabolism and Pharmacokinetics, Jiangsu Key Laboratory of Drug Design and Optimization, China Pharmaceutical University, Nanjing 210009, China; ${ }^{2}$ State Key Laboratory of Phytochemistry and Plant Resources in West China, Kunming Institute of Botany, Chinese Academy of Sciences, Kunming 650201, China; ${ }^{3}$ Department of Pharmacology, Clinical Research Institute of Jiangsu Provincial Hospital of Traditional Chinese Medicine, Nanjing 210009, China; ${ }^{4}$ Collaborative Innovation Center of Advanced Drug Delivery System and Biotech Drugs in Universities of Shandong, Pharmacy School at Yantai University, Yantai 264005, China

\begin{abstract}
Berberrubine (BRB) is the primary metabolite of berberine (BBR) that has shown a stronger glucose-lowering effect than BBR in vivo. On the other hand, BRB is quickly and extensively metabolized into berberrubine-9-0- $\beta$ - $D$-glucuronide (BRBG) in rats after oral administration. In this study we compared the pharmacokinetic properties of BRB and BRBG in rats, and explored the mechanisms underlying their glucose-lowering activities. C57BL/ 6 mice with HFD-induced hyperglycemia were administered BRB $\left(50\right.$ mg.kg ${ }^{-1} \cdot \mathrm{d}^{-1}$, ig) for 6 weeks, which caused greater reduction in the plasma glucose levels than those caused by BBR $\left(120 \mathrm{mg}^{\mathrm{k}} \mathrm{kg}^{-1} \cdot \mathrm{d}^{-1}\right) \mathrm{or} \mathrm{BRB}(25$ $\left.\mathrm{mg} \cdot \mathrm{kg}^{-1} \cdot \mathrm{d}^{-1}\right)$. In addition, BRB dose-dependently decreased the activity of $\alpha$-glucosidase in gut of the mice. After oral administration of $B R B$ in rats, the exposures of BRBG in plasma at 3 different dosages $(10,40,80 \mathrm{mg} / \mathrm{kg})$ and in urine at different time intervals $(0-4$, 4-10, 10-24 h) were dramatically greater than those of BRB. In order to determine the effectiveness of BRBG in reducing glucose levels, we prepared BRBG from the urine pool of rats, and identified and confirmed it through LC-MS-IT-TOF and NMR spectra. In human normal liver cell line L-O2 in vitro, treatment with BRB or BRBG $(5,20,50 \mu \mathrm{mol} / \mathrm{L})$ increased glucose consumption, enhanced glycogenesis, stimulated the uptake of the glucose analog 2-NBDG, and modulated the mRNA levels of glucose-6-phosphatase and hexokinase. However, both BBR and BRB improved 2-NBDG uptake in insulin-resistant L-O2 cells, while BRBG has no effect. In conclusion, BRB exerts a stronger glucose-lowering effect than BBR in HFD-induced hyperglycemia mice. Although BRB significantly stimulated the insulin sensitivity and glycolysis in vitro, BRBG may have a greater contribution to the glucose-lowering effect because it has much greater system exposure than BRB after oral administration of BRB. The results suggest that BRBG is a potential agent for reducing glucose levels.
\end{abstract}

Keywords: hyperglycemia; glucose-lowering effect; berberine; berberrubine; glucuronide; $\alpha$-glycosidase; HFD-induced hyperglycemia model of C57BL/6 mice; human normal liver cell line L-02; pharmacokinetics

Acta Pharmacologica Sinica (2017) 38: 351-361; doi: 10.1038/aps.2016.120; published online 2 Jan 2017

\section{Introduction}

Berberine (BBR), together with palmatine and jatrorrhizine, is an effective alkaloid isolated from the herb Rhizoma coptidis (RC), which is used in traditional Chinese medicine ${ }^{[1]}$. As a major component of RC, BBR has drawn extensive attention recently because of its wide range of effects such as antiinflammatory, lipid-lowering, anti-tumor, and anti-diabetic

*To whom correspondence should be addressed:

E-mail: jiyea@cpu.edu.cn

Received 2016-06-12 Accepted 2016-09-27 effects, among others ${ }^{[2-5]}$. In vivo studies have revealed that berberrubine (BRB) is the primary metabolite of 9-demethylated BBR that may have potential pharmacological activities ${ }^{[6]}$. In fact, BRB showed good antibiosis ${ }^{[7]}$, anti-inflammatory effects $^{[8]}$, in addition to antioxidant effect on human fibrosarcoma cells ${ }^{[9]}$ and the scavenging effect of reactive oxidative species $(\mathrm{ROS})^{[10]}$. Pharmacokinetics studies also indicated that BRB had more efficient intestinal absorption and bioavailability than $\mathrm{BBR}^{[11]}$.

Glucuronidation is the one of the most common Phase II conjugation reactions in the drug metabolizing system ${ }^{[12]}$. 
Many drugs, such as metoclopramide, chloramphenicol, p-aminobenzoic acid, and zidovudine, can be metabolized into their respective glucuronides ${ }^{[13-16]}$. Fortunately, morphine6-glucuronied possesses similar pharmacological activity as morphine and has been successfully developed as a frontline analgesic drug.

Our pilot study showed that BRB possessed stronger lipidlowering and glucose-lowering effects than BBR. However, $B R B$ was quickly and extensively metabolized into BRB-glucuronide (BRBG) in rats after oral administration, which was supported by the previous studies that showed that BRB could be metabolized into its corresponding glucuronide mainly by UGT1A1 and UGT2B1 in rats ${ }^{[17]}$. We found at three different dosages that the in vivo exposure of BRBG was dozens of times greater than that of BRB in terms of the AUC achieved. We also found that BRB could be extensively eliminated from urine in its glucuronide form. Considering the distinct pharmacological activities of quercetin-glucuronide, bisphenol A $\beta$-D-glucuronide and morphine-6-glucuronide ${ }^{[18-21]}$ and the anti-microbial activity of the derivatives synthesized from BRB, eg, 9-O-acyl-and 9-O-alkyberberrubine ${ }^{[22]}$, the effect of BRBG on lipid and glucose modulation greatly attracted our interest as well. Thus, in this study, we focused on the pharmacokinetics and glucose-lowering effect of BRB and on the potential pharmacological activities of 9-O-glucuronide-berberrubine. To obtain the trial chemical, we first prepared and purified berberrubine-9-O- $\beta-D$-glucuronide from the urine pool of rats treated with BRB. Chemical identification was made using liquid chromatography combined with hybrid ion trap and time-of-flight mass spectrometry (LC-MS-ITTOF) and further confirmed with nuclear magnetic resonance (NMR) spectra. The pharmacokinetics of BRB, including the effect of BRB on glucose levels, were assessed in a high-fatdiet-induced hyperglycemia model of C57BL/6 mice. Additionally, the glucose-lowering effect of BRBG in vitro was evaluated in an L-O2 cell line.

\section{Materials and methods Reagents}

BRB (purity $>95 \%$ ) and demethyleneberberine (DMB, purity $>95 \%)$ were synthetized by ChemzamPharmtech Co (Nanjing, China). BBR (purity $>99 \%$ ) and fexofenadine (purity $>99 \%$ ) were purchased from the National Institute for the Control of Pharmaceutical and Biological Products (Beijing, China). Acetonitrile, formic acid and methanol (chromatography grade) were purchased from Merch (Darmstadt, Germany) or Fisher (Waltham, MA, USA). A mouse a-glucosidase ELISA kit was purchased from Senbeijia Biological Technology (Nanjing, China), and a glucose test kit was obtained from Nanjing Jiancheng Bioengineering Institute (Nanjing, China). 2-NBDG (2-(N-(7-nitrobenz-2-oxa-1,3-diazol-4-yl) amino)2-deoxyglucose) was obtained from Invitrogen (Carlsbad, CA, USA). Fetal bovine serum (FBS) and Dulbecco's modified Eagle's medium (DMEM) were purchased from Gibco (Grand Island, USA). All other reagents were purchased from SigmaAldrich (St Louis, MO, USA, or Steinhein, Germany).
Glucose-lowering effect of BBR and its metabolites on a high-fatdiet-induced hyperglycemia model of C57BL/ 6 mice

The protocols for the animal studies were approved by the Animal Ethics Committee of China Pharmaceutical University. C57BL/ 6 mice (male; six weeks old; weighing 18-22 g; from the College of Animal Science and Technology, Yangzhou University, China) were housed at a temperature of $22^{\circ} \mathrm{C}$ to $24^{\circ} \mathrm{C}$ with a 12 -h light-dark cycle. The humidity was maintained at $60 \%$. Mice were fed with a control diet (AIN93M, Trophic Animal Feed High-tech Co, Ltd, China) or a high-fat diet (HFD, 60\% calories from fat and 1\% cholesterol, Trophic Animal Feed High-tech Co, Ltd, China). After three weeks, the HFD group was randomly assigned to the HFD and experimental groups. Berberine $(120 \mathrm{mg} / \mathrm{kg})$, berberrubine (high dose group: $50 \mathrm{mg} / \mathrm{kg}$; low dose group: $25 \mathrm{mg} / \mathrm{kg}$ ), and DMB $(180 \mathrm{mg} / \mathrm{kg})$ were intragastrically administered to the experimental groups for six weeks, continuing with the HFD diet $(n=5)$. After treatment, mice were fasted for $12 \mathrm{~h}$, and blood samples were collected. Plasma glucose levels were then determined. Small intestine mucosa was gently isolated on an ice plate and weighed. A 1.0-g portion of the mucosa was placed in a test tube with $1 \mathrm{~mL}$ of PBS, homogenized, and centrifuged at $2300 \times \mathrm{g}$ for $20 \mathrm{~min}$ at $4^{\circ} \mathrm{C}$. The middle layer was collected, and a-glucosidase activity was determined by the ELISA kit.

\section{Pharmacokinetics studies on BRB after oral administration in} rats

Sprague Dawley (SD) rats (male, 200-220 g, 6-7 weeks) purchased from Shanghai Sippr BK Laboratory Animals Ltd (Shanghai, China) were intragastrically administered with different dosages of BRB (low dosage, $10 \mathrm{mg} / \mathrm{kg}$; middle dosage, $40 \mathrm{mg} / \mathrm{kg}$; high dosage, $80 \mathrm{mg} / \mathrm{kg}$ ). Plasma samples were collected at intervals of $0,0.083,0.167,0.25,0.5,1,1.5,2,3,6,8,12$, and $24 \mathrm{~h}$ after oral administration and centrifuged at $5000 \times \mathrm{g}$ for $10 \mathrm{~min}$ to separate the plasma. Another six SD rats were housed in metabolic cages with free access to water and food and intragastrically administered with BRB $(40 \mathrm{mg} / \mathrm{kg})$ once. Urine samples were collected at $0-4 \mathrm{~h}, 4-10 \mathrm{~h}$, and 10-24 h. All the samples were stored at $-80^{\circ} \mathrm{C}$ for later analysis.

\section{Preparation of berberrubine-9-0- $\beta$ - $D$-glucuronide Purification and purity analysis of BRBG}

After oral administration of BRB in Sprague Dawley rats, urine samples were collected and pooled, and methanol was added $(1: 4, v / v)$ for precipitation. The mixture was vortexed, filtered, and evaporated in a Speed-vac Concentrator (SavantInstrument, Framingdale, NY, USA) at room temperature. The supernatant was injected into a Shimadzu LC-MS 2010A system (Shimazu Corporation, Kyoto, Japan). The system contained two ADVP pumps, a vacuum deaerator, an automatic sampler, an Electron Spray Ionization (ESI) ion source, a Quadrupole mass spectrometry detector and a PDA detector. The maximum wavelength of UV-absorption was determined by an LC-MS-PDA system for further preparation needs.

A Shimadzu (Shimazu Corporation, Kyoto, Japan) prepara- 
tive HPLC system (containing LC-20AP pumps, an SPD$20 \mathrm{~A}$ detector and a CBM-20A controller ) was connected with a YMC-Pack ODS-A column $(250 \times 20 \mathrm{~mm}, 5 \mu \mathrm{m}$, Japan $)$ for preparation, isolation and online monitoring of components in urine. The detection wavelength was set at $344 \mathrm{~nm}$ as a result of LC-MS-PDA determination. Isocratic elution was carried out with acetonitrile:water $(2: 8, v / v)$ at a flow rate of 10 $\mathrm{mL} / \mathrm{min}$. The eluted mobile fraction at different time intervals was collected, freeze-dried and subjected to the repeated preparative isolation. Afterward, purity analysis was carried out by using the LC-MS-PDA system with a detection wavelength of $254 \mathrm{~nm}$.

\section{Structure identification of BRBG}

A Shimadzu LC-MS-IT-TOF system (containing a CBM-20A controller, an SIL-20AC automatic sampler, LC-20AB pumps, an SPD-M20A detector, etc) was used to analyze the MS1 and MS2 fragment ions to analyze the structure of the target compound. ${ }^{1} \mathrm{H}$ NMR spectra were measured on an AVANCE AV-500 spectrometer (Bruker BioSpin Group, Switzerland), and the target compound was dissolved in DMSO- $\mathrm{d}_{6}$.

\section{Hydrolyzation of BRBG in gut flora}

The cecal contents of C57BL/ 6 mice were collected and mixed with a boiled aqueous solution ( $20 \%$ glycerol and $1.8 \%$ sodium chloride) at a ratio of 1:3 (g:mL). All samples were prepared in a sterile environment. The gut flora were diluted by Poly Peptone Yeast Extract Medium $(v / v, 1: 10)$ and cultured at $37^{\circ} \mathrm{C}$ and $200 \mathrm{r} / \mathrm{min}$ for $12 \mathrm{~h}$ to promote anaerobic bacteria proliferation. The medium was made according to a previously established method ${ }^{[23]}$. A total of $10 \mu \mathrm{L}$ of BRBG solution (2, 20, and $200 \mu \mathrm{mol} / \mathrm{L})$ was added to $90 \mu \mathrm{L}$ of the fermented gut content and control flora; $i e$, the gut content was boiled for de-activation $(n=3)$. The mixture in sterile tubes was put into a sealed can with a bio-bag and shaken at $37^{\circ} \mathrm{C}$ and $200 \mathrm{r} / \mathrm{min}$ for $30 \mathrm{~min}$. To each tube, $300 \mu \mathrm{L}$ of acetonitrile containing 10 $\mathrm{ng} / \mathrm{mL}$ of internal standard was added, vortexed and centrifuged at $12000 \times g$ for $10 \mathrm{~min}$. The supernatant was transferred and analyzed.

\section{LC-MS/MS conditions}

The LC-MS/MS method was carried out using a Shimadzu Ultra Performance LC-20A system (Shimazu Corporation, Kyoto, Japan) connected with AB SCIEX (Applied Biosystems, Forster City, CA, USA) and an API4000 Triple Quadrupole Mass Spectrometer equipped with a turbo ion-spray ionization source. Analyst 1.5.2 (AB SCIEX) was used for instrument control, data acquisition and analysis. Chromatographic separation was done on a Waters Atlantis T3 column $(2.1 \mathrm{~mm} \times 100$ $\mathrm{mm}, 3 \mu \mathrm{m}$ particle size, Waters, USA) with the column temperature set at $40^{\circ} \mathrm{C}$. The mobile phases containing phase A ( $0.1 \%$ formic acid in water) and phase B (acetonitrile) were eluted at a flow rate of $0.2 \mathrm{~mL} / \mathrm{min}$. The gradient was as follows: $25 \%$ B maintained for $1 \mathrm{~min}$, increased to $60 \% \mathrm{~B}$ at $7 \mathrm{~min}$, returned to initial conditions for $0.5 \mathrm{~min}$, and then re-equilibrated for $2 \mathrm{~min}$. The mass spectrometer parameters were set as follows: spray voltage, $5500 \mathrm{~V}$; Curtain Gas (CUR), $35 \mathrm{Arb}$; Ion source Gas 1 (GS1), 50 Arb; and Ion source Gas 2 (GS2), 55 Arb. The electrospray ionization source was operated in the positive mode. Compounds were detected in MRM monitoring conditions. The transitions of $\mathrm{m} / \mathrm{z} 322.4 \rightarrow 307.1$ (Declustering Potential: $80 \mathrm{~V}$; Collision Energy: $34 \mathrm{eV}$ ), $\mathrm{m} / \mathrm{z} 498.3 \rightarrow 322.1$ (DP: $80 \mathrm{~V}, \mathrm{CE}: 30 \mathrm{eV}$ ) and $\mathrm{m} / \mathrm{z}$ 502.4 $\rightarrow 466.3$ (DP: $100 \mathrm{~V}, \mathrm{CE}: 27$ $\mathrm{eV})$ were monitored for BRB, BRBG and the internal standard (Fexofenadine), respectively.

\section{Cell viability assay}

L-O2 cells (Chinese Typical Culture Collection Center) were cultured in Dulbecco's modified Eagle's medium (DMEM) containing $10 \%$ fetal serum in a 96 -well plate at a density of 5000 cells/well. The incubator was kept at $37^{\circ} \mathrm{C}$ and in a saturated humidified atmosphere of $5 \% \mathrm{CO}_{2}$. The cells were incubated for $24 \mathrm{~h}$ and then exposed to BRB and BRBG at a concentration ranging from 5 to $50 \mu \mathrm{mol} / \mathrm{L}$ for $24 \mathrm{~h}$, with a vehicle control $(n=5)$. After $24 \mathrm{~h}$ of treatment, the medium was removed, and $150 \mu \mathrm{L}$ of working solution of MTT (3-(4,5-dimethylthiazol-2-yl)-2,5-diphenyl tetrazolium bromide, $0.5 \mathrm{mg} / \mathrm{mL}$ ) was added to each well and incubated for $4 \mathrm{~h}$ at $37^{\circ} \mathrm{C}$. Formazan crystals were dissolved in DMSO after the medium was removed and then read at $490 \mathrm{~nm}$ on a BioTek synergy H1 plate reader (BioTek Instruments Inc, Winooski, VT, USA).

\section{Glucose consumption}

The cells were suspended in $0.25 \%$ trypsin and plated on a 96 -well plate in DMEM containing 10\% fetal serum. The glucose consumption was determined following the modified method of Zheng et al ${ }^{[24]}$. After the cells reached the proper density, the medium was removed and replaced by fresh DMEM (glucose level of $5.5 \mathrm{mmol} / \mathrm{L}$ ) containing test compounds at different concentrations. As the positive control group, $50 \mu \mathrm{mol} / \mathrm{L}$ of BBR was used. The test compound groups contained BRB $(5,20$, and $50 \mu \mathrm{mol} / \mathrm{L})$ and BRBG $(5,20$, and $50 \mu \mathrm{mol} / \mathrm{L})(n=5)$. Water and DMSO were also compared in the control group. After $24 \mathrm{~h}$, glucose surplus was measured by a glucose kit at $505 \mathrm{~nm}$. Glucose consumption was calculated by using the remaining glucose level in the medium and the initial glucose level.

\section{2-NBDG uptake in L-02 cells}

L-O2 cells were cultured in DMEM containing $10 \%$ fetal serum and plated on 96-well fluorescence plates to reach a proper density. The cells were exposed to different groups of BBR $(50 \mu \mathrm{mol} / \mathrm{L}), \mathrm{BRB}(50 \mu \mathrm{mol} / \mathrm{L})$ and BRBG $(50 \mu \mathrm{mol} / \mathrm{L})$. The control group was also prepared. After incubation for $24 \mathrm{~h}$, the medium was removed, and the cells were incubated with PBS containing $100 \mu \mathrm{mol} / \mathrm{L}$ of the fluorescent glucose analog 2-NBDG for another $60 \mathrm{~min}$. The assay was implemented according to a previously reported method ${ }^{[25]}$ with a slight modification. After incubation, free 2-NBDG was washed out by cool phosphate buffer solution (PBS) three times. A fluorescence microscope (Leica, Germany) was used to compare 
the uptake of 2-NBDG in different groups, and the samples were observed under the GEP fluorescence channel.

\section{Insulin sensitivity test}

L-O2 cells were cultured and incubated on six-well fluorescence plates with $2 \mathrm{~mL}$ of DMEM for each well. When a proper density was reached, the test groups were pretreated with DMEM (without fetal serum) containing $1 \mu \mathrm{mol} / \mathrm{L}$ insulin in the presence of BBR, BRB, BRBG or metformin for $24 \mathrm{~h}$. The model group was incubated with $1 \mu \mathrm{mol} / \mathrm{L}$ of insulin only, and the control group was cultured in DMEM without insulin $(n=3)$. After $24 \mathrm{~h}$, the test groups and insulin stimulation group (without insulin pretreatment) were exposed to 100 $\mathrm{nmol} / \mathrm{L}$ insulin containing $100 \mu \mathrm{mol} / \mathrm{L}$ 2-NBDG for another $60 \mathrm{~min}$. The supernatant mixture was washed out three times with PBS. The values of 2-NBDG uptake in the presence or absence of insulin were used to evaluate the insulin sensitivity of different groups by using the BioTek synergy H1 plate reader (excitation wavelength: $485 \mathrm{~nm}$; emission wavelength: $535 \mathrm{~nm})$.

\section{RNA isolation and quantitative real-time PCR}

Total RNA was obtained using the TRIzol method ${ }^{[26]}$. Total RNA was reverse-transcribed into cDNA following the manufacturer's protocol (Takara). SYBR Premix ExTaq II (Takara) was used in the reaction with cDNA samples under the CFX96 RT-PCR detection system with a C1000 thermal cycler (BioRad, USA). $\beta$-Actin was used as the endogenous control following the PCR procedural cycle: $95^{\circ} \mathrm{C}$ for 3 min and 40 cycles of $95^{\circ} \mathrm{C}$ for $10 \mathrm{~s}$, annealing at $60^{\circ} \mathrm{C}$ for $30 \mathrm{~s}$, and $72^{\circ} \mathrm{C}$ for $30 \mathrm{~s}$.

\section{Determination of glycogen content}

The glycogen contents of different groups were measured using a glycogen determination kit modified from the previous method ${ }^{[27]}$. L-O2 cells were cultured in six-well culture plates and exposed to BBR, BRB and BRBG with the same concentration of $50 \mu \mathrm{mol} / \mathrm{L}(n=3)$. After incubation for $24 \mathrm{~h}$, the cells were retrieved using alkaline solution, and developer was added. The mixture was boiled and then examined at 620 nm.

\section{Statistical analysis}

Experimental data were analyzed using the one-way ANOVA method with SPSS 16.0 software (SPSS Institute, Chicago, USA). If the level of $P<0.05$, then the groups were considered to have statistical significance. Data were expressed as the mean \pm SD (standard deviation), and each group had at least three experiments performed in triplicate.

\section{Results}

Glucose-lowering effect of berberine metabolites on high-fat-diet -induced hyperglycemia in mice

The animal model of high-fat-diet (HFD)-induced hyperglycemia or insulin resistance has been widely used in the assessment of glucose-lowering effects ${ }^{[28,29]}$. After 9 weeks of continuous feeding with HFD, the glucose level in the plasma of the HFD mice was significantly elevated $(12.17 \pm 1.70$ vs $6.52 \pm 1.83 \mathrm{mmol} / \mathrm{L}, P<0.01)$. The experimental groups of C57BL/ 6 mice were intragastrically administered with BBR and its two main metabolites, BRB and DMB. After 6 weeks of oral administration, the treatment with BRB at high dosage (50 $\mathrm{mg} / \mathrm{kg}$ ) produced the most significant decrease in the glucose level $(6.63 \pm 1.67 \mathrm{mmol}, P<0.01)$. BBR $(120 \mathrm{mg} / \mathrm{kg})$ and BRB at the low dosage $(25 \mathrm{mg} / \mathrm{kg})$ showed similar glucose-lowering effects compared to the HFD group $(9.35 \pm 1.60,8.84 \pm 2.03$ $\mathrm{mmol} / \mathrm{L}, P<0.05)$. However, administration of another BBR metabolite, DMB, at a much higher dosage $(180 \mathrm{mg} / \mathrm{kg})$ than $B R B$ did not show a significant difference compared with the HFD control (Figure 1A). The results indicated that BRB was one of the active metabolites of BBR, exhibiting a marked and stronger effect on glucose lowering compared with BBR. To further investigate the potential mechanism of BRB on the glucose-lowering effect, small intestine mucosa was isolated, and gut a-glucosidase activity was measured. It was shown that treatment with BBR and BRB significantly inhibited the activity of gut a-glucosidase (Figure 1B). Additionally, BRB showed a dose-dependent activity on a-glucosidase. Since a-glucosidase is a carbohydrate-hydrolase, ie, it can break down starch and disaccharides to glucose, the inhibition effect of BRB on a-glucosidase indicated that BRB could prevent
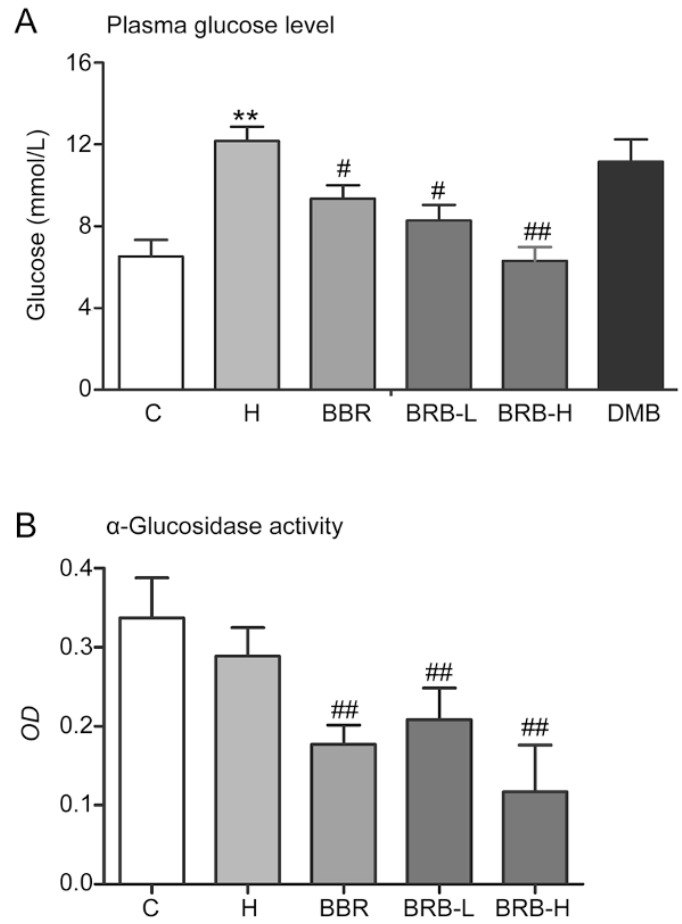

Figure 1. Glucose-lowering effect of BBR metabolites on high-fat diet induced hyperglycemia in mice. (A) The plasma glucose level. (B) $\alpha$-glucosidase activity in small intestine mucosa. C, C57BL/6 mice with normal standard diet; $\mathrm{H}$, high-fat diet group; $\mathrm{BRB}$, berberrubine; $\mathrm{BBR}$, highfat diet+BBR (120 mg.kg $\cdot \mathrm{d}^{-1}$ ); BRB-L, high-fat diet+BRB (25 mg.kg $\cdot \mathrm{d}^{-1}$ ); BRB-H, high-fat diet+BRB (50 mg. $\left.\mathrm{kg}^{-1} \cdot \mathrm{d}^{-1}\right)$; DMB, high-fat diet+DMB (180 mg.kg $\cdot \mathrm{d}^{-1}$ ). Values are mean \pm SD. $n=5$. ${ }^{* *} P<0.01$ vs $C$. ${ }^{\#} P<0.05$, \# $P<0.01$ vs H. 
polysaccharides in food from being absorbed through the gut into the circulatory system, partially explaining the glucoselowering effect of BRB.

\section{Pharmacokinetics studies on BRB after oral administration in rats}

$\mathrm{BRB}$ is the primary metabolite of BBR, and some previous studies revealed that BRB could be metabolized into its glucuronide BRBG (Figure 2) ${ }^{[30]}$. The pharmacokinetic characteristics of BRB were evaluated after SD rats were orally administered with BRB at different dosages (low dosage, 10 $\mathrm{mg} / \mathrm{kg}$; middle dosage, $40 \mathrm{mg} / \mathrm{kg}$; high dosage, $80 \mathrm{mg} / \mathrm{kg}$ ). Plasma samples were analyzed with LC-MS/MS. Surprisingly, BRB could be quickly and extensively metabolized into its glucuronide at a high proportion (Figure S1); ie, the area under the plasma concentration-time curve (AUC) of BRBG is dramatically higher than that of BRB (Figure 3). The values of $\mathrm{AUC}_{\mathrm{BRBG}} / \mathrm{AUC}_{\mathrm{BRB}}$ at different concentrations were also calculated (data not shown). Based on the high metabolic velocity and transformation rate of BRB to BRBG, we presumed that BRBG was an active Phase II metabolite of BRB, which partially contributed to the pharmacological activity.

Many drugs could be conjugated with glucuronic acid, allowing these more hydrophilic compounds to be more easily excreted in urine ${ }^{[31,32]}$. Quantitative analysis of BRBG and BRB in urine at intervals of 0-4 h, 4-10 h, and 10-24 h was also performed to further understand the pharmacokinetic characteristics of BRB. For quantitative assay of BRBG, urine was collected and pooled after the rats were treated with BRB. An LC/MS preparation was employed, and the BRBG portion was chromatographically isolated and refined. Finally, BRBG was prepared and identified using LC/IT-TOF-MS together with NMR. Quantitative analysis of BRB and BRBG showed that the absolute amounts of BRBG $(0-4 \mathrm{~h}, 60.8 \pm 6.1 \mu \mathrm{g} / \mathrm{mL} ; 4-10 \mathrm{~h}$, $121.0 \pm 4.5 \mu \mathrm{g} / \mathrm{mL} ; 10-24 \mathrm{~h}, 5.8 \pm 0.4 \mu \mathrm{g} / \mathrm{mL})$ in urine samples were all much higher than that of BRB (0-4 h, 305.3 \pm 36.1 $\mathrm{ng} / \mathrm{mL} ; 4-10 \mathrm{~h}, 710.8 \pm 43.5 \mathrm{ng} / \mathrm{mL} ; 10-24 \mathrm{~h}, 185.9 \pm 20.0 \mathrm{ng} / \mathrm{mL})$ at the three different time intervals (Figure 4A-4C). These results indicated that $\mathrm{BRB}$ could be quickly and extensively metabolized into BRBG and eliminated through urine largely in forms of BRBG in SD rats (Figure 4D, 4E).

\section{Preparation of berberrubine-9-0- $\beta-D$-glucuronide Collection and LC-MS-PDA analysis of BRBG in urine}

As determined in the pilot study, the pharmacokinetic studies on BRB showed that the urinary accumulation of BRBG in plasma and urine was much higher than that of BRB. Therefore, urine samples were collected, pooled, and injected into the preparative HPLC system. An ESI positive scan using the LC-MS-PDA showed a distinct peak at $4.4 \mathrm{~min}$ (Figure S2A). Both the fragment ions (at $m / z 498.2$ and 321.9) and the UV spectra (absorption peak $\lambda_{\max }$ in the regions of $240-280 \mathrm{~nm}$ and 300-380 nm) of the peak showed consistency with those of BRBG $^{[30]}$ (Figure S2B, S2C). Therefore, the mobile phase of the peak was collected and enriched repeatedly for purification and further identification.

\section{Purification and structure identification of BRBG prepared from urine samples}

The enriched extracts from urine samples were injected into the preparative HPLC system for further isolation and purification of BRBG. Three primary peaks at different retention times in the preparative column appeared, and their peak interval elutes were collected and analyzed in the LC-MS-PDA (Figure S3). It was shown that the peak at 14 min exhibited the same characteristics in the mass spectrum and UV spectrum as BRBG. Therefore, the elute fraction at $14 \mathrm{~min}$ was collected, freeze-dried and examined for purity analysis (94.98\%, Table S1) and structure identification.

As the high-resolution mass spectrum of LC-MS-IT-TOF indicated, the compound was detected as protonated molecular ion $[\mathrm{M}+\mathrm{H}]^{+}$at $m / z 498.1378\left(\mathrm{C}_{25} \mathrm{H}_{23} \mathrm{NO}_{10}[\mathrm{M}+\mathrm{H}]^{+}\right)$in the positive mode, corresponding to its molecular mass of $497 \mathrm{Da}$ $\left(\mathrm{C}_{25} \mathrm{H}_{23} \mathrm{NO}_{10}\right)$ (Figure $\mathrm{S} 4$ ). This parent ion produced fragments at $m / z$ 322.1058 and 307.0874, which were considered as MS $^{2}$ fragments. The characteristic fragment ion at 322.1058 possessed the absolutely highest intensity. As the most abundant fragment, the product ion $\mathrm{m} / \mathrm{z} 322.1058$ was dominated by the neutral loss of $176 \mathrm{Da}$ (glucuronic acid residue, $\mathrm{C}_{6} \mathrm{H}_{8} \mathrm{O}_{6}$ ) from its precursor ion $m / z$ 498.1378. The fragment ion at $m / z$ $322.1058\left(\mathrm{C}_{19} \mathrm{H}_{15} \mathrm{NO}_{4}[\mathrm{M}+\mathrm{H}]^{+}\right)$corresponded to its molecular formula $\mathrm{C}_{19} \mathrm{H}_{15} \mathrm{NO}_{4}$ (molecular mass, $321 \mathrm{Da}$ ), which was consistent with that of BRB. Therefore, this compound was pro-<smiles>COc1ccc2cc3[n+](cc2c1OC)CCc1cc2c(cc1-3)OCO2</smiles>

Figure 2. Metabolic pathway for the glucuronidation of BRB. 
A

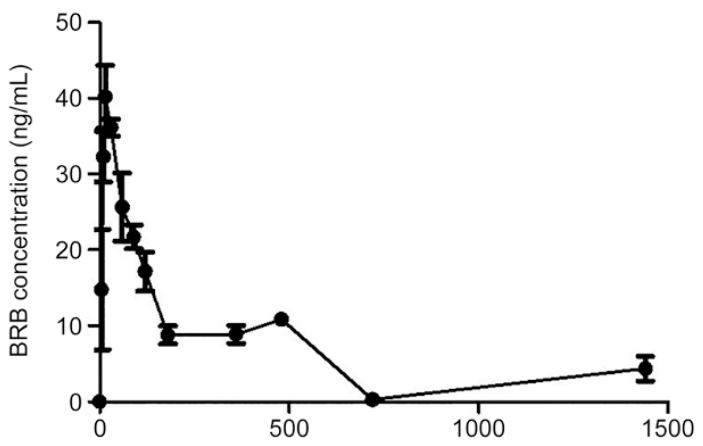

B

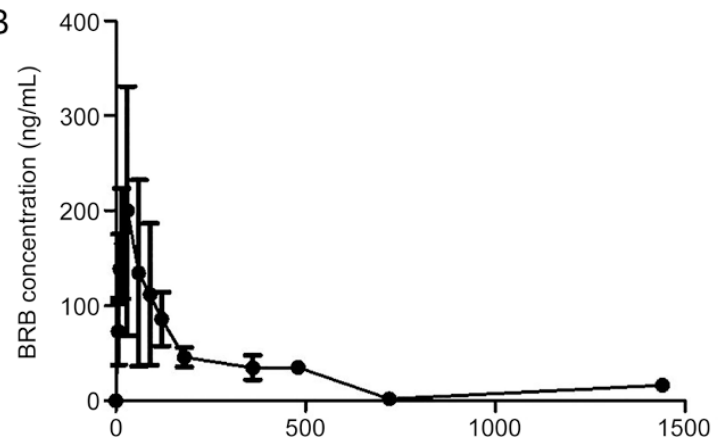

C

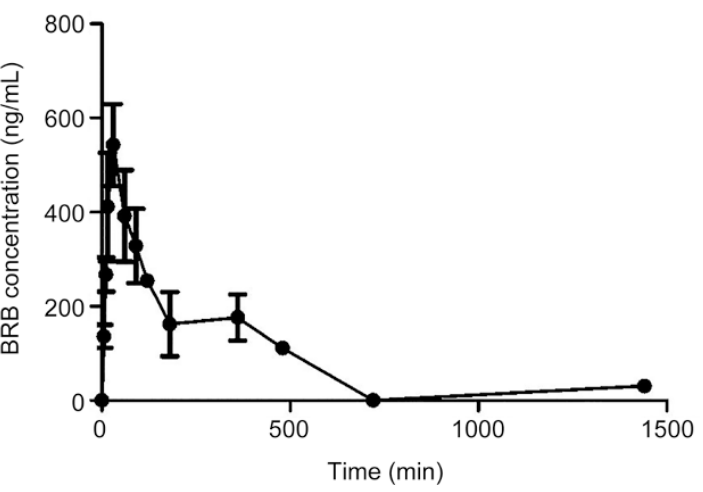

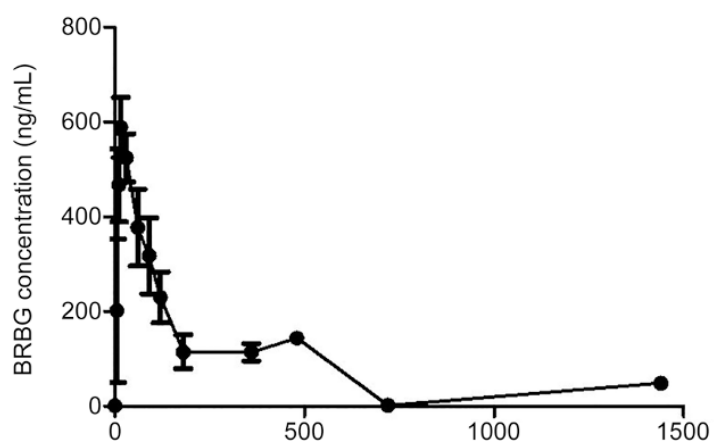
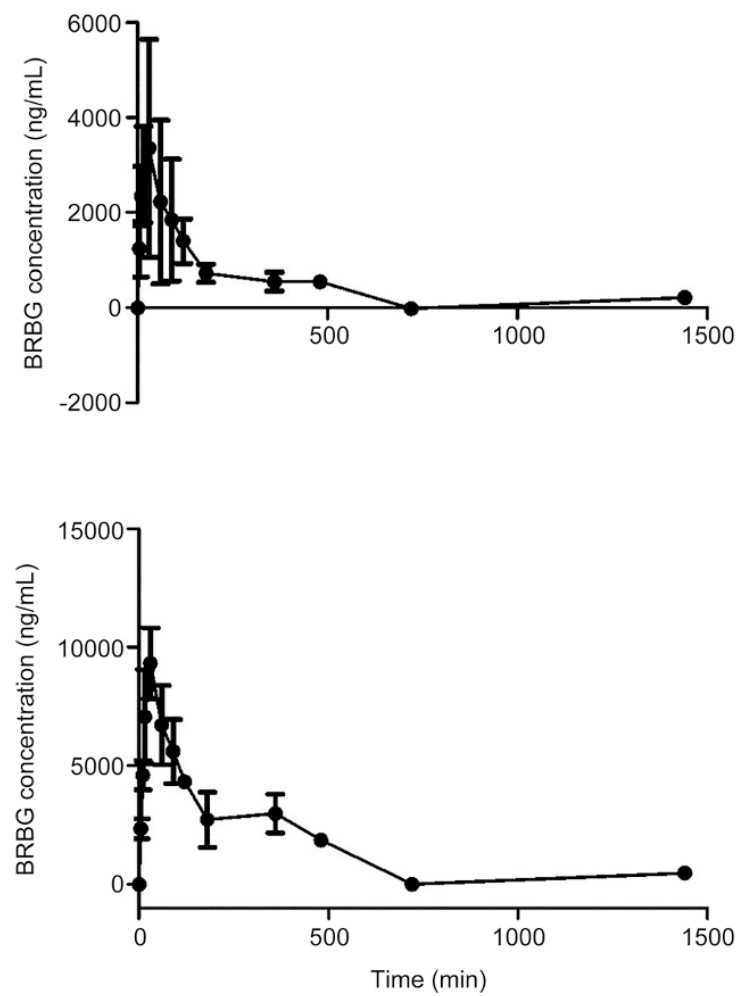

Figure 3. Plasma concentration-time curves of $B R B$ and BRBG after oral administration of BRB in SD rats. BRB, berberrubine. (A) Low dose, 10 mg/kg; (B) Middle dose, $40 \mathrm{mg} / \mathrm{kg}$; (C) High dose, $80 \mathrm{mg} / \mathrm{kg}$. Values are mean \pm SD. $n=3$.

posed to be the glucuronide of BRB, and the phenolic hydroxyl group at the C9-site could most easily be conjugated with the glucuronic acid residue, as shown in Figure 2. To further confirm the structure, NMR analysis was performed and a comparison was made with the published data of $\mathrm{BRBG}^{[30]}$. It was shown that the ${ }^{1} \mathrm{H}$ NMR spectrum of the purified extracts matched well with the published data (Table 1). Initially, the ${ }^{1} \mathrm{H}$ NMR spectrum of the target compound showed six hydrogen signals down field at $\delta_{\mathrm{H}} 10.09(1 \mathrm{H}, \mathrm{s}), 8.87(1 \mathrm{H}, \mathrm{s}), 8.16(1 \mathrm{H}$, $\mathrm{d}, 8.6 \mathrm{~Hz}), 8.00(1 \mathrm{H}, \mathrm{d}, 9.1 \mathrm{~Hz}), 7.75(1 \mathrm{H}, \mathrm{s})$ and $7.08(1 \mathrm{H}, \mathrm{s})$ due to the berberine hydrogens at the $C(8), C(13), C(11), C(12), C(1)$ and $\mathrm{C}(4)$ positions. At the same time, the hydrogen signals of the terminal group of glucuronic acid were also found at $\delta \mathrm{H}$ $4.90(1 \mathrm{H}, \mathrm{d}, 7.6 \mathrm{~Hz})$, further suggesting that the target compound might be the glucuronic acid metabolite of berberine.
Ultimately, the ${ }^{1} \mathrm{H}$ NMR data of the target compound agreed with that of berberrubine-9-O- $\beta-D$-glucuronide through database searching ${ }^{[30]}$, so the target compound was identified as berberrubine-9-O- $\beta-D$-glucuronide.

\section{Hydrolyzation of BRBG in gut flora}

As our previous pharmacokinetics study in Figure 3 indicated, both BRB and BRBG showed shoulder peaks, which indicates the possibility of enterohepatic circulation and metabolic interconversion. There are thousands of species present in the gut, and the numerous hydrolases encoded by these species are very important for metabolic homeostasis. $\beta$-Glucuronidase is a hydrolase that targets the glucuronidated compounds, releasing glucuronic acid ${ }^{[33]}$. As our previous study indicated, large amounts of BRB and BRBG could be detected in bile after 

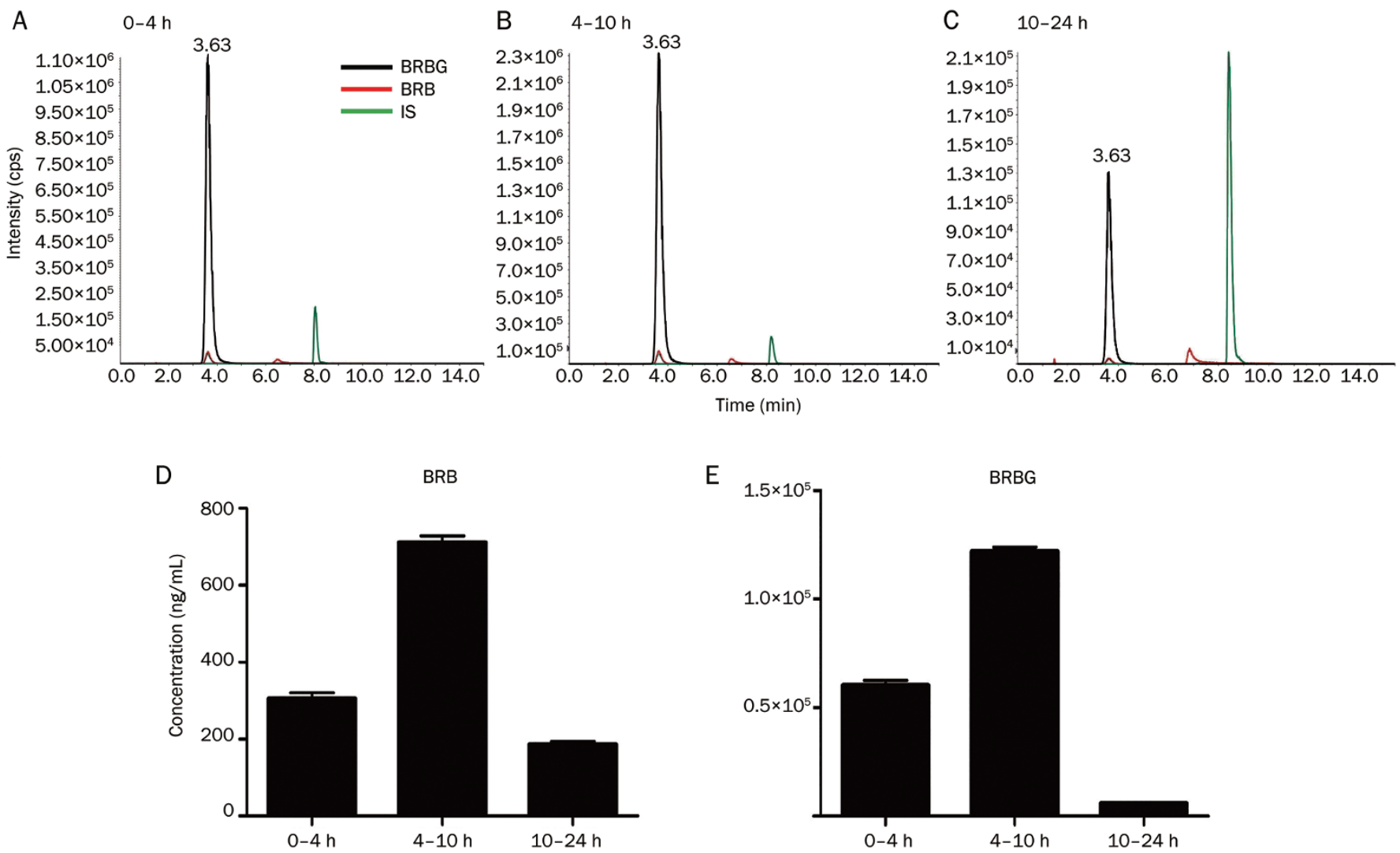

Figure 4. Extraction ion current chromatograms of BRB, BRBG, and their concentrations in urine samples. SD rats were intragastrically administered with BRB of $40 \mathrm{mg} / \mathrm{kg}$. MRM chromatogram of urine samples at intervals of $4 \mathrm{~h}(\mathrm{~A}), 10 \mathrm{~h}(\mathrm{~B}), 24 \mathrm{~h}(\mathrm{C})$. BRB at $\mathrm{m} / z$ 322.4 $\rightarrow 307.1$, BRBG at $\mathrm{m} / \mathrm{z}$ $498.3 \rightarrow 322.1$ and IS at $m / z 502.4 \rightarrow 466$.3. Ion peaks are located at $t_{R} 3.63 \mathrm{~min}$ (BRBG), $6.85 \mathrm{~min}$ (BRB), and 8.26 min (IS), respectively. Quantitative analysis of BRB (D) and BRBG (E) in urine samples at different time intervals are shown as mean \pm SD. $n=6$.

Table 1. ${ }^{1} \mathrm{H}$ NMR data of target compound compared with berberine and berberrubine-9-O- $\beta$-D-glucuronide.

\begin{tabular}{|c|c|c|c|}
\hline Proton № & Berberine $^{[30]}$ & $\begin{array}{l}\text { Chemical shift }\left(\delta_{H}\right) \\
\text { Berberrubine-9-O- } \beta-D \text {-glucuronide }^{[30]}\end{array}$ & Target compound \\
\hline 1 & $7.79(1 \mathrm{H}, \mathrm{s})$ & $7.77(1 \mathrm{H}, \mathrm{s})$ & $7.75(1 \mathrm{H}, \mathrm{s})$ \\
\hline 4 & $7.09(1 \mathrm{H}, \mathrm{s})$ & $7.1(1 \mathrm{H}, \mathrm{s})$ & $7.08(1 \mathrm{H}, \mathrm{s})$ \\
\hline 5 & $3.22(2 \mathrm{H}, \mathrm{t}, 5.6 \mathrm{~Hz})$ & $3.24(2 \mathrm{H}, \mathrm{o})$ & $3.20(2 \mathrm{H}, 0)$ \\
\hline 6 & $4.95(2 \mathrm{H}, \mathrm{t}, 5.6 \mathrm{~Hz})$ & $5.1(1 \mathrm{H}, \mathrm{m}) ; 4.85(1 \mathrm{H}, \mathrm{m})$ & $5.02-5.05(1 \mathrm{H}, \mathrm{m}) ; 4.87-4.91(1 \mathrm{H}, \mathrm{m})$ \\
\hline 12 & $8.01(1 \mathrm{H}, \mathrm{d}, 8.7 \mathrm{~Hz})$ & $8.04(1 \mathrm{H}, \mathrm{d}, 9.2 \mathrm{~Hz})$ & 8.00 \\
\hline 13 & $8.96(1 \mathrm{H}, \mathrm{s})$ & $8.89(1 \mathrm{H}, \mathrm{s})$ & $8.87(1 \mathrm{H}, \mathrm{s})$ \\
\hline $2,3-\mathrm{OCH}_{2} \mathrm{O}$ & $6.17(2 \mathrm{H}, \mathrm{s})$ & $6.18(2 \mathrm{H}, \mathrm{s})$ & $6.17(2 \mathrm{H}, \mathrm{s})$ \\
\hline $9-\mathrm{OCH}_{3}$ & $4.10(3 \mathrm{H}, \mathrm{s})$ & - & - \\
\hline $10-\mathrm{OCH}_{3}$ & $4.07(3 \mathrm{H}, \mathrm{s})$ & $4.04(3 \mathrm{H}, \mathrm{s})$ & $4.03(3 \mathrm{H}, \mathrm{s})$ \\
\hline
\end{tabular}

The spectra of target compound was recorded on an AV-500 spectrometer in DMSO- $\mathrm{d}_{6}$. s, singlet; d, doublet; t, triplet; m, multiplet; o, overlapped; GlcUA, glucuronic acid.

BRB oral administration, but BRBG could be barely detected in feces (unpublished data). Based on this evidence, we incubated BRBG with the gut flora and found that a large amount of BRBG could be quickly hydrolyzed at three different concentrations $(0.2,2$, and $20 \mu \mathrm{mol} / \mathrm{L})$, wherein BRB increased consistently (Figure 5). However, in the control group, there 
A

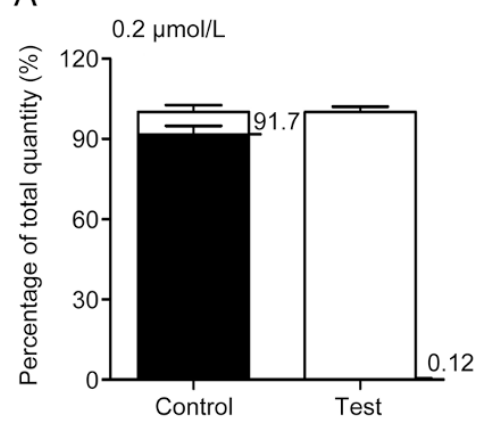

B

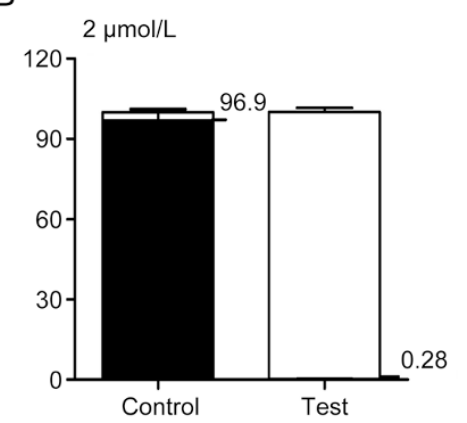

C

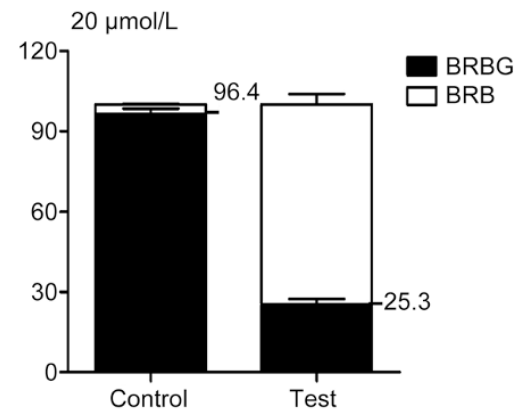

Figure 5. The relative percentage of BRB and BRBG after the incubation of BRBG in gut content. BRBG was incubated in the cecal contents of $\mathrm{C} 57 \mathrm{BL} / 6$ mice at three different concentrations $(0.2,2$, and $20 \mu \mathrm{mol} / \mathrm{L})$ for $30 \mathrm{~min}$. The flora in gut content of the test group showed distinct hydrolysis activity for BRBG, while the flora in gut content of the control group was boiled and de-activated. The percentage of BRB and BRBG to the total quantity (BRB+BRBG) are shown as mean \pm SD. $n=3$.

A

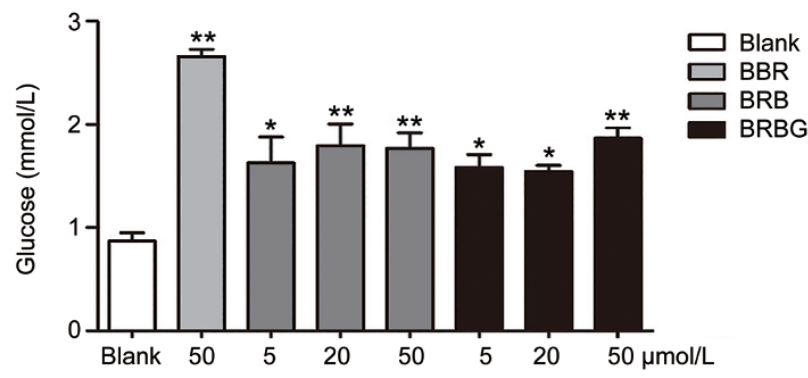

C
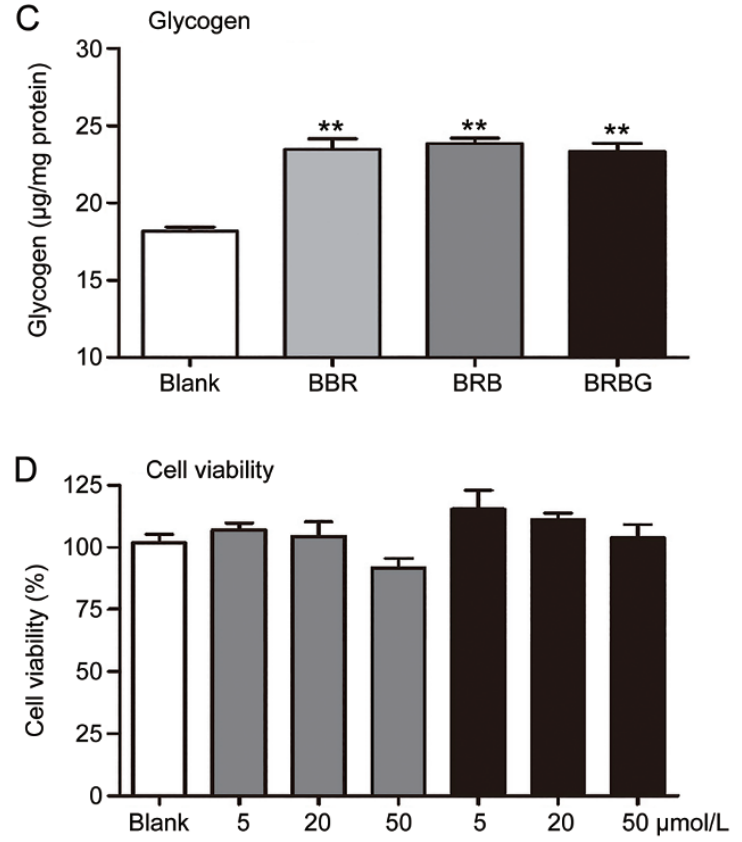

B 2-NBDG uptake
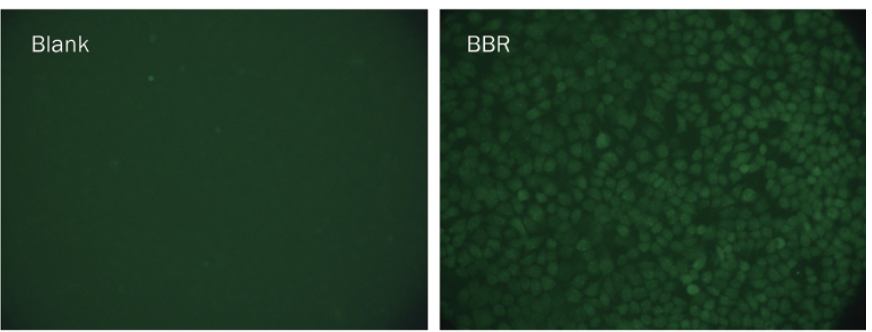

BRB

BRBG

Figure 6. Glucose-lowering effect of BRB and BRBG in L-O2 cells. (A) Glucose consumption of BRBG and BRB in L-O2 cells ( $n=5$ ), where BBR ( 50 $\mu \mathrm{mol} / \mathrm{L}$ ) was used as the positive group. L-O2 cells were exposed to BRB or BRBG at 5, 20 and $50 \mu \mathrm{mol} / \mathrm{L}$, respectively. (B) The uptake of 2-NBDG into L-O2 cells. Fluorescent image of cells incubated with Blank medium, $50 \mu \mathrm{mol} / \mathrm{L} \mathrm{BBR,} 50 \mu \mathrm{mol} / \mathrm{L} \mathrm{BRB}, 50 \mu \mathrm{mol} / \mathrm{L}$ BRBG for $24 \mathrm{~h}$. After pretreatment, each group was exposed to $100 \mu \mathrm{mol} / \mathrm{L}$ 2-NBDG for $60 \mathrm{~min}$. (C) Glycogen content of different groups (Blank; BBR, $50 \mu \mathrm{mol} / \mathrm{L}$; BRB, $50 \mu \mathrm{mol} / \mathrm{L}$; BRBG, $50 \mu \mathrm{mol} / \mathrm{L})$. Values are mean \pm SD. $n=3$. (D) The effect of BRB and BRBG $(5,20$, and $50 \mu \mathrm{mol} / \mathrm{L})$ on $\mathrm{L}-02$ cells viability. Mean $\pm S D$. $n=5$. ${ }^{*} P<0.05$, ${ }^{* *} P<0.01$ vs Blank control. 
was not any apparent hydrolyzation.

\section{BRB and BRBG enhanced glucose consumption and glycogenesis} in vitro

The purified BRBG was examined for its glucose-lowering effect, which was compared with that of BRB. Measurement of glucose in media cultured with the L-O2 cell line showed that both BRB ( $5 \mu \mathrm{mol} / \mathrm{L}, P<0.05 ; 20$ and $50 \mu \mathrm{mol} / \mathrm{L}, P<0.01)$ and BRBG (5 and $20 \mu \mathrm{mol} / \mathrm{L}, P<0.05 ; 50 \mu \mathrm{mol} / \mathrm{L}, P<0.01$ ) significantly increased the glucose consumption to a similar extent compared to the vehicle controls. BBR was used as the positive control (50 $\mathrm{mmol} / \mathrm{L}, P<0.01)$ (Figure 6A). Furthermore, BRB and BRBG (both $50 \mu \mathrm{mol} / \mathrm{L}$ ) stimulated the uptake of the fluorescent glucose analog 2-NBDG (Figure 6B) and increased the glycogen content by $31 \%$ and $28 \%$, respectively (Figure 6C). No cytotoxicity was observed in L-O2 cells at the concentrations tested by means of the cell viability assay (Figure 6D). Further studies suggested that BRB and BRBG modu- lated the mRNA levels of glucose-6-phosphatase (G6Pase) and hexokinase $(\mathrm{HK})$, the two pivotal enzymes of glucose metabolism (Figure 7A) and decreased G6Pase in vitro, indicating the inhibitory effect on the hydrolyzation of glucose 6-phosphate to glucose.

BRB stimulated insulin sensitivity by enhancing 2-NBDG uptake in insulin resistant L-O2 cells

To determine whether BRB and its glucuronide BRBG have the potential to decrease the glucose level by stimulating insulin sensitivity, an insulin resistant model was implemented on L-O2 cells (Figure 7B). After incubation with excess insulin $(1 \mathrm{~mol} / \mathrm{L})$ in advance, insulin at proper concentration (100 $\mathrm{nmol} / \mathrm{L}$ ) was added to the model cells to stimulate 2-NBDG uptake. As the result indicated, the model cells showed significant insulin resistance compared to the control (without preincubation with excessive insulin). In insulin-resistant L-O2 cells, 2-NBDG uptake was remarkably improved by incuba-
A
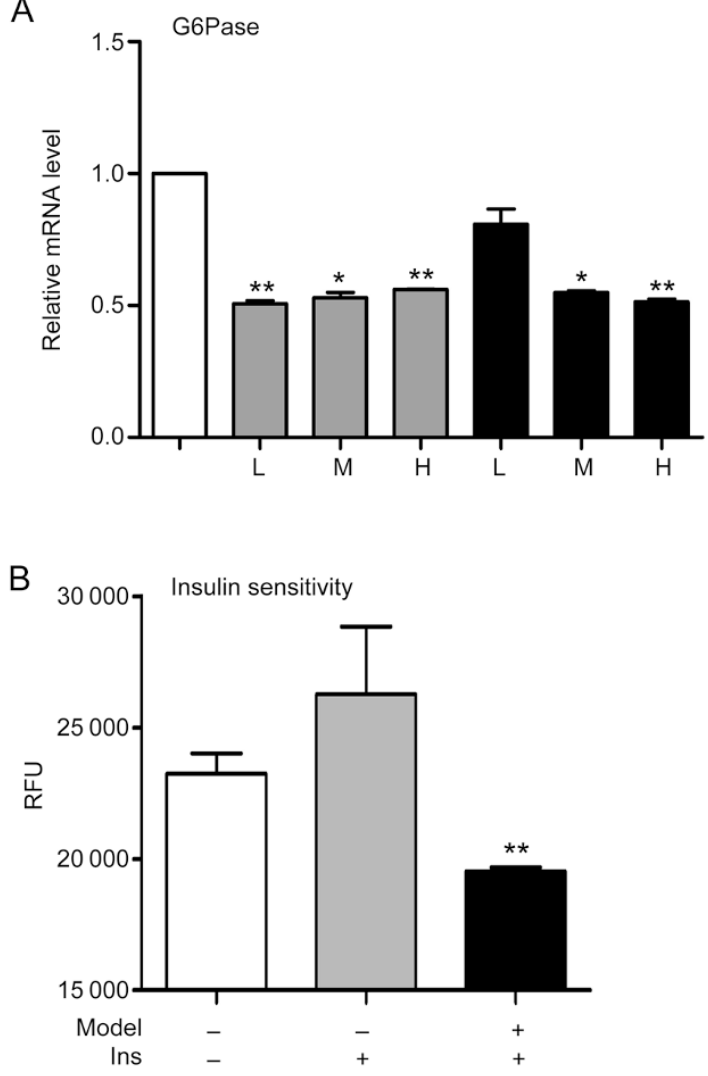
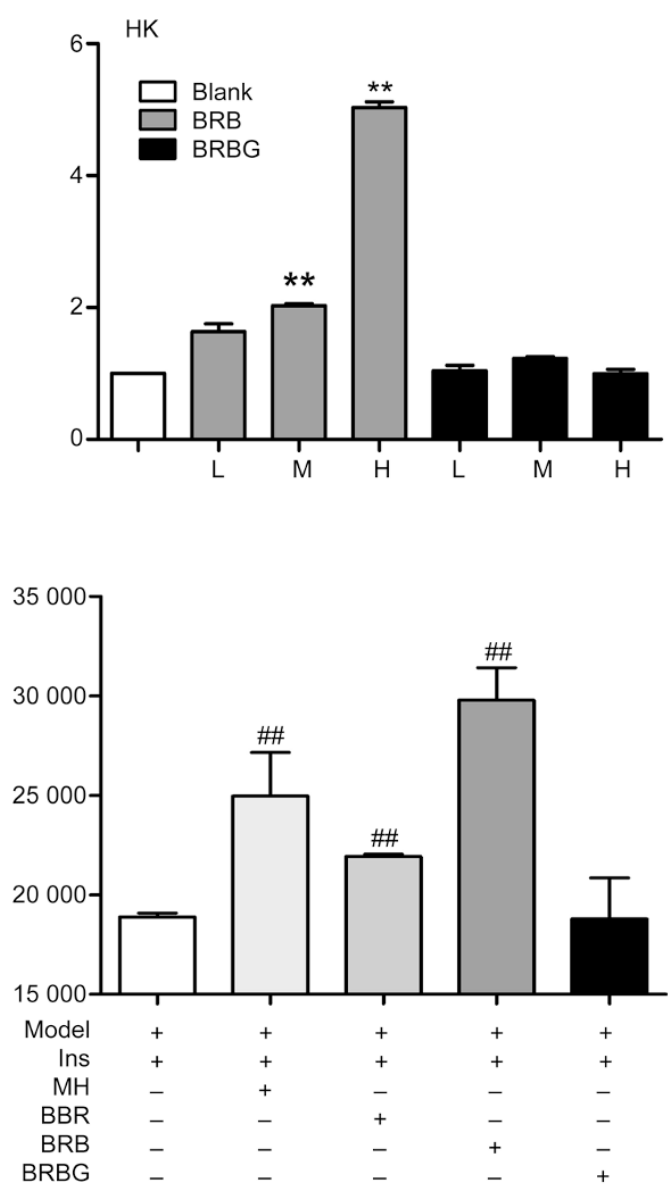

Figure 7. The effect of BRB and BRBG on glucose metabolism and insulin sensitivity. (A) The effect of BRB and BRBG on mRNA expression of key enzymes in glucose metabolism in HepG2 cells. The mRNA levels of glucose-6-phosphatase (G6Pase) and hexokinase (HK) were normalized to that of $\beta$-actin. L, $5 \mu \mathrm{mol} / \mathrm{L} ; \mathrm{M}, 20 \mu \mathrm{mol} / \mathrm{L} ; \mathrm{H}, 50 \mu \mathrm{mol} / \mathrm{L}$. ${ }^{*} \mathrm{P}<0.05,{ }^{* *} \mathrm{P}<0.01 \mathrm{vs}$ Blank control. (B) The effect of BRB and BRBG on 2-NBDG uptake in insulinresistant L-O2 cells. L-O2 cells were incubated with $1 \mu \mathrm{mol} / \mathrm{L}$ insulin for $24 \mathrm{~h}$ to establish insulin-resistant model (Model) and test groups were co-incubated with BBR, BRB, and BRBG at $50 \mu \mathrm{mol} / \mathrm{L}$, respectively. Cells were then stimulated with $100 \mathrm{nmol} / \mathrm{L}$ insulin for 60 min to determine the uptake of 2-NBDG (Ins). Metformin (MH) at $10 \mu \mathrm{mol} / \mathrm{L}$ was used as the positive group. ${ }^{* *} P<0.01$ vs Model-Ins+. ${ }^{\# \#} P<0.01$ vs Model+Ins+. Results are represented as mean \pm SD. $n=3$. 
tion with BBR and BRB at $50 \mu \mathrm{mol} / \mathrm{L}$, but BRBG did not show a distinct effect. As the positive control, metformin promoted 2-NBDG uptake to some extent at $10 \mu \mathrm{mol} / \mathrm{L}(P<0.01)$.

\section{Discussion}

It has been well documented that BBR is poorly absorbed via gastrointestinal administration, yet it shows a positive effect on hypolipidemia and hypoglycemia ${ }^{[34]}$. As the primary metabolite of BBR, few studies have focused on the pharmacological effects of BRB. Our present study showed that $B R B$ remarkably reduced the glucose level of high-fat-dietinduced hyperglycemic C57BL/6 mice (Figure 1A) and that it even had a stronger effect than that of BBR. For the first time, we have found that BRB significantly inhibited the activity of a-glucosidase and thus prevented the uptake of polysaccharides into the circulation system (Figure 1B), indicating the important mechanism of the glucose-lowering efficacy of BRB.

This study revealed that the bioavailability of BRB was much greater than that of its parent compound, BBR, suggesting a better drug adaptability of BRB. Interestingly, our data showed that BRB was quickly and extensively metabolized into glucuronide after its oral administration in rats. Furthermore, BRB and BRBG showed very similar PK curves with a synchronous $T_{\max }$. However, the $C_{\max }$ and AUC of BRBG were much higher than those of $B R B$, indicating a much greater exposure level of BRBG than BRB. Moreover, both BRB and BRBG showed shoulder peaks, indicating an enterohepatic cycle of BRB and BRBG. Accordingly, we also confirmed that BRBG could be quickly hydrolyzed into BRB after incubation with gut flora. In other words, orally administered BRB could be quickly and extensively metabolized into BRBG in the liver. On the other hand, BRBG could be rapidly hydrolyzed in gut flora such that BRB was produced and re-absorbed in the intestine. Therefore, it was suggested that an oral administration of BRBG had the same pharmacological effect as BRB.

Both BRB and BRBG significantly enhanced glucose consumption and glycogenesis in vitro and influenced two key enzymes of glucose metabolism (Figure 6, 7). It is possible that BRBG can be recognized as an active metabolite contributing to the glucose-lowering effect of BRB. Although BBR showed a stronger effect on glucose consumption and 2-NBDG uptake than BRB and BRBG at the same concentration in vitro, the exposed concentration of BBR in the liver is much less than this dosage because of poor bioavailability ${ }^{[35]}$. This may help to explain the lower glucose-lowering effect of BBR in vivo compared with BRB. Since high-fat-diet-induced obesity could result in insulin resistance ${ }^{[36]}$ and the liver, as an important tissue, interacts with insulin to play an important role in glucose metabolism ${ }^{[37]}$, we established an insulin-resistant model by using the human normal liver cell line L-O2 (Figure 7B). Although BRBG did not show obvious activity in promoting insulin sensitivity compared with $B R B$, our previous study also confirmed that BRBG could be largely hydrolyzed into BRB in gut flora. Therefore, after being re-absorbed in the intestine in the form of BRB, BRBG could also exert similar pharmacological effects.
In summary, our data suggested that BRB had a stronger glucose-lowering effect than BBR, and it showed distinct inhibition on a-glucosidase in the gut. Pharmacokinetic results revealed that BRB was rapidly metabolized into BRBG, which was much more highly exposed than BRB in vivo. As the glucuronide of BRB, BRBG enhanced glucose consumption, 2-NBDG uptake and glycogen content on L-O2 cells. It was suggested that BRBG may play an important role in the glucose-lowering effect of orally administered BRB.

\section{Acknowledgements}

This study was financially supported by the National Natural Science Foundation of China (№ 81573495, 81530098), the Key Technology Projects of China "Creation of New Drugs" (№ 2015ZX09501001), the Project for Jiangsu Province Key Lab of Drug Metabolism and Pharmacokinetics (№ BM2012012) and the Project of the University Collaborative Innovation Center of Jiangsu Province (Modern Chinese Medicine Center and Biological Medicine Center).

\section{Author contribution}

Ji-ye AA contributed to the development of the project and experimental design; Na YANG contributed to the design and performance of experiments; Run-bin SUN contributed to the animal experiment and paper preparation; Xing-long CHEN, Le ZHEN, and Jian-liang GENG contributed to the preparation and structure analysis of the target compound; Chun GE helped to complete the qRT-PCR; Yu-qing ZHAO, Jun HE, Jiahua GUO, and Xiao-yi YU participated in the animal experiment and data analysis; Fei FEI and Si-qi FENG contributed to the animal experiment; and Guang-ji WANG, Xuan-xuan ZHU, Feng-hua FU, and Hong-bo WANG contributed to the data analysis and manuscript writing. All authors read and approved the final manuscript.

\section{Supplementary information}

Supplementary information is available at website of Acta Pharmacologica Sinica.

\section{References}

1 Wang D, Liu Z, Guo M, Liu S. Structural elucidation and identification of alkaloids in Rhizoma Coptidis by electrospray ionization tandem mass spectrometry. J Mass Spectrom 2004; 39: 1356-65.

2 Li HM, Wang YY, Wang HD, Cao WJ, Yu XH, Lu DX, et al. Berberine protects against lipopolysaccharide-induced intestinal injury in mice via alpha 2 adrenoceptor-independent mechanisms. Acta Pharmacol Sin 2011; 32: 1364-72.

3 Holy EW, Akhmedov A, Luscher TF, Tanner FC. Berberine, a natural lipid-lowering drug, exerts prothrombotic effects on vascular cells. J Mol Cell Cardiol 2009; 46: 234-40.

4 Wang ZS, Lu FE, Xu LJ, Dong $\mathrm{H}$. Berberine reduces endoplasmic reticulum stress and improves insulin signal transduction in HepG2 cells. Acta Pharmacol Sin 2010; 31: 578-84.

5 Pan GY, Wang GJ, Sun JG, Huang ZJ, Zhao XC, Gu Y, et al. Inhibitory action of berberine on glucose absorption. Acta Pharm Sin 2003; 38: 911-4.

6 Spinozzi S, Colliva C, Camborata C, Roberti M, lanni C, Neri F, et al. 
Berberine and its metabolites: relationship between physicochemical properties and plasma levels after administration to human subjects. J Nat Prod 2014; 77: 766-72.

7 Park KD, Lee JH, Kim SH, Kang TH, Moon JS, Kim SU. Synthesis of 13-(substituted benzyl) berberine and berberrubine derivatives as antifungal agents. Bioorg Med Chem Lett 2006; 16: 3913-6.

8 Cui HS, Hayasaka S, Zhang XY, Hayasaka Y, Chi ZL, Zheng LS. Effect of berberrubine on interleukin-8 and monocyte chemotactic protein-1 expression in human retinal pigment epithelial cell line. Life Sci 2006; 79: 949-56.

9 Pongkittiphan V, Chavasiri W, Supabphol R. Antioxidant effect of berberine and its phenolic derivatives against human fibrosarcoma cells. Asian Pac J Cancer Prev 2015; 16: 5371-6.

10 Jang MH, Kim HY, Kang KS, Yokozawa T, Park JH. Hydroxyl radical scavenging activities of isoquinoline alkaloids isolated from Coptis chinensis. Arch Pharm Res 2009; 32: 341-5.

11 Wang X, Wang S, Ma J, Ye T, Lu M, Fan M, et al. Pharmacokinetics in rats and tissue distribution in mouse of berberrubine by UPLC-MS/ MS. J Pharm Biomed Anal 2015; 115: 368-74.

12 Strassburg CP, Strassburg A, Kneip S, Barut A, Tukey RH, Rodeck B, et al. Developmental aspects of human hepatic drug glucuronidation in young children and adults. Gut 2002; 50: 259-65.

13 Argikar UA, Gomez J, Ung D, Parkman HP, Nagar S. Identification of novel metoclopramide metabolites in humans: in vitro and in vivo studies. Drug Metab Dispos 2010; 38: 1295-307.

14 Fedeniuk RW, Mizuno M, Neiser C, O'Byrne C. Development of LCMS/MS methodology for the detection/determination and confirmation of chloramphenicol, chloramphenicol 3-O-beta-d-glucuronide, florfenicol, florfenicol amine and thiamphenicol residues in bovine, equine and porcine liver. J Chromatogr B Analyt Technol Biomed Life Sci 2015; 991: 68-78.

15 Chan K, Miners JO, Birkett DJ. Direct and simultaneous high-performance liquid chromatographic assay for the determination of $p$ aminobenzoic acid and its conjugates in human urine. J Chromatogr 1988; 426: 103-9.

16 Nagaoka K, Hanioka N, Ikushiro S, Yamano S, Narimatsu S. The effects of $\mathrm{N}$-glycosylation on the glucuronidation of zidovudine and morphine by UGT2B7 expressed in HEK293 cells. Drug Metab Pharmacokinet 2012; 27: 388-97.

17 Liu Y, Hao H, Xie H, Lv H, Liu C, Wang G. Oxidative demethylenation and subsequent glucuronidation are the major metabolic pathways of berberine in rats. J Pharm Sci 2009; 98: 4391-401.

18 Wang LL, Zhang ZC, Hassan W, Li Y, Liu J, Shang J. Amelioration of free fatty acid-induced fatty liver by quercetin-3-O- $\beta$ - $D$-glucuronide through modulation of peroxisome proliferator-activated receptoralpha/sterol regulatory element-binding protein-1c signaling. Hepatol Res 2016; 46: 225-38.

19 Boucher JG, Boudreau A, Ahmed S, Atlas E. In vitro effects of bisphenol A beta- $D$-glucuronide (BPA-G) on adipogenesis in human and murine preadipocytes. Environ Health Perspect 2015; 123: 1287-93.

20 Mikus G, Klimas R. Relative contribution of morphine and morphine6-glucuronide to the analgesic effect after morphine administration. Br J Anaesth 2015; 114: 1007.

21 Sverrisdottir E, Lund TM, Olesen AE, Drewes AM, Christrup LL, Kreilgaard M. A review of morphine and morphine-6-glucuronide's pharmacokinetic-pharmacodynamic relationships in experimental and clinical pain. Eur J Pharm Sci 2015; 74: 45-62.

$22 \mathrm{Kim} \mathrm{SH}$, Lee SJ, Lee JH, Sun WS, Kim JH. Antimicrobial activity of 9-Oacyl- and 9-O-alkylberberrubine derivatives. Planta Med 2002; 68: 277-81.

23 Zhao C, Sun R, Cao B, Gu S, Zhao J, Liu L, et al. An in vitro metabolic system of gut flora and the metabolism of ginsenoside Rg3 and cholic acid. Eur J Drug Metab Pharmacokinet 2014; 39: 129-37.

24 Zheng XK, Li YJ, Zhang L, Feng WS, Zhang X. Antihyperglycemic activity of Selaginella tamariscina (Beauv.) Spring. J Ethnopharmacol 2011; 133: 531-7.

25 Alonso-Castro AJ, Salazar-Olivo LA. The anti-diabetic properties of Guazuma ulmifolia Lam are mediated by the stimulation of glucose uptake in normal and diabetic adipocytes without inducing adipogenesis. J Ethnopharmacol 2008; 118: 252-6.

26 Mannhalter C, Koizar D, Mitterbauer G. Evaluation of RNA isolation methods and reference genes for RT-PCR analyses of rare target RNA. Clin Chem Lab Med 2000; 38: 171-7.

27 Fang HJ. A rapid enzymic method for glycogen estimation in very small tissue samples. Clin Chim Acta 1970; 30: 567-72.

28 Benzler J, Ganjam GK, Pretz D, Oelkrug R, Koch CE, Legler K, et al. Central inhibition of IKKbeta/NF-kappaB signaling attenuates highfat diet-induced obesity and glucose intolerance. Diabetes 2015; 64: 2015-27.

29 Bandyopadhyay GK, Lu M, Avolio E, Siddiqui JA, Gayen JR, Wollam $\mathrm{J}$, et al. Pancreastatin-dependent inflammatory signaling mediates obesity-induced insulin resistance. Diabetes 2015; 64: 104-16.

30 Qiu F, Zhu Z, Kang N, Piao S, Qin G, Yao X. Isolation and identification of urinary metabolites of berberine in rats and humans. Drug Metab Dispos 2008; 36: 2159-65.

31 Takikawa H, Beppu T, Seyama Y. Profiles of bile acids and their glucuronide and sulphate conjugates in the serum, urine and bile from patients undergoing bile drainage. Gut 1985; 26: 38-42.

32 Mutsaers HA, Wilmer MJ, Reijnders D, Jansen J, van den Broek $\mathrm{PH}$, Forkink $\mathrm{M}$, et al. Uremic toxins inhibit renal metabolic capacity through interference with glucuronidation and mitochondrial respiration. Biochim Biophys Acta 2013; 1832: 142-50.

33 Gloux K, Anba-Mondoloni J. Unique beta-glucuronidase locus in gut microbiomes of Crohn's disease patients and unaffected first-degree relatives. PloS One 2016. doi: 10.1371/journal.pone.0148291.

34 Pirillo A, Catapano AL. Berberine, a plant alkaloid with lipid- and glucose-lowering properties: from in vitro evidence to clinical studies. Atherosclerosis 2015; 243: 449-61.

35 Gu S, Cao B, Sun R, Tang Y, Paletta JL, Wu X, et al. A metabolomic and pharmacokinetic study on the mechanism underlying the lipidlowering effect of orally administered berberine. Mol Biosyst 2015; 11: 463-74.

36 Ballak DB, van Diepen JA, Moschen AR, Jansen HJ, Hijmans A, Groenhof GJ, et al. IL-37 protects against obesity-induced inflammation and insulin resistance. Nat Commun 2014; 5: 4711.

37 Schafer A, Neschen S, Kahle M, Sarioglu H, Gaisbauer T, Imhof A, et al. The epoxyeicosatrienoic acid pathway enhances hepatic insulin signaling and is repressed in insulin-resistant mouse liver. Mol Cell Proteomics 2015; 14: 2764-74. 